\title{
Agreement Between 64-Slice Multidetector CT Angiography and Transthoracic Echocardiography in Detection of Extracardiac Findings of Congenital Heart Disease
}

\author{
Adeel Asghar Malik, Furqan Ahmad, Sameera Amir, Javaid Asgher and Khalid Farooq \\ Department of Radiology, Doctors Hospital and Medical Centre, Lahore, Pakistan
}

\begin{abstract}
Objective: To determine the degree of agreement between multi-detector computed tomography angiography and transthoracic echocardiography in diagnostic evaluation of congenital heart disease with extracardiac findings.

Study Design: Descriptive cross-sectional study.

Place and Duration of Study: Radiology Department, Doctors Hospital and Medical Centre, Lahore, from May to November 2016.

Methodology: Patients with clinical suspicion of cardiovascular malformation were included in the study. All the patients had echocardiography and thoracic computed tomography angiography done to diagnose congenital heart disease. Agreement was labelled in true positive and true negative patients.

Results: Computed tomography angiography could detect the extracardiac findings of congenital heart disease in 140 (93.3\%) patients, while transthoracic echocardiography in $118(78.7 \%)$ patients. Agreement was detected in $108(72 \%)$ patients. Kappa statistics showed poor agreement (kappa $=-0.113$ ).

Conclusion: Although transthoracic echocardiography is usually the first line of investigation in evaluation of congenital heart disease; it has its limitations for evaluating congenital heart disease with extracardiac findings, due to intrinsic limitation of the imaged field. Computed tomography angiography has better sensitivity in detecting extracardiac findings of congenital heart disease along with better delineation of anatomy.
\end{abstract}

Key Words: Multi-detector computed tomography, Transthoracic echocardiography, Angiography.

How to cite this article: Malik AA, Ahmad F, Amir S, Asgher J, Farooq K. Agreement between 64-slice multidetector CT angiography and transthoracic echocardiography in detection of extracardiac findings of congenital heart disease. J Coll Physicians Surg Pak 2019; 29(10):923-7.

\section{INTRODUCTION}

Congenital heart diseases (CHD) include major structural malformations of the heart and/or major vessels present at, or persisting abnormally after birth. ${ }^{1} \mathrm{CHD}$ is the most common congenital anomaly 2,3 , with a global incidence of 8 in 1000 live births. 4,5 CHD accounts for around $1 \%$ of live births. ${ }^{6}$ However, a recent study done by Ariane J. et al. showed that there is $50 \%$ increase in incidence of CHD by 2010.7 The incidence of congenital heart disease in Pakistan has been estimated 4 in 1000 live births. ${ }^{8}$ Many of them need surgical procedure in early life. 9 Cardiac surgery itself has significant mortality rate of $6.3 \% .10$ Fifteen percent of abortions done worldwide are due to CHD. ${ }^{11}$ Congenital heart disease with extracardiac findings includes major structural

Correspondence to: Dr. Adeel Asghar Malik, Department of Radiology, Doctors Hospital and Medical Centre, 152 Johar

Town, Lahore, Pakistan

E-mail:malikimation@yahoo.com

Received: October 31, 2018; 'Revised: May 07, 2019;

Accepted: June 27, 2019 malformations of the heart and/or major vessels present at or persisting abnormally after birth.

The prenatal detection rate $(\mathrm{n}=1912)$ increased with $23.9 \%$ (95\% confidence interval 19.5 - 28.3) from 35.8 to $59.7 \%$ after the introduction of screening and of isolated CHD with $21.4 \%\left(95 \% \mathrm{Cl} 16.0\right.$ - 26.8) from 22.8 to $44.2 \% .{ }^{12}$ Survival rates and life expectancy has significantly improved for patients with congenital heart disease and these patients are now frequently reaching reproductive age. ${ }^{13}$ Recurrence rates for CHD have been estimated at $3 \%$ to $5 \% .13$

Transthoracic echocardiography (TTE) is the first-line tool for diagnosis and follow-up of paediatric and young adult patients with CHD.14,15 In addition to being highly operator dependent, echocardiography may not be sufficient for evaluating extracardiac structures, such as the pulmonary arteries, pulmonary veins, aortic arch and great vessels due to acoustic window limitations. ${ }^{16}$ Cardiac catheter angiography is also used to evaluate CHD, but it is an invasive procedure with its own set of complications. ${ }^{17}$ Four-dimensional (4D) flow is emerging 
as a single fast technique for comprehensive assessment of CHD. 18

Recently, multi-detector computed tomography (MDCT) angiography (CTA) and magnetic resonance angiography (MRA) are practiced as additional 7 modalities. MDCT CTA can be used for accurate depiction of complex cardiovascular anatomic features both before and after surgery and to delineate variety of post-treatment complications. ${ }^{16}$

A study done by Duan $\mathrm{YH}$, et al. showed an agreement of $84 \%$ between CT and TTE in evaluation of congenital heart disease. ${ }^{19}$ Due to its clinical significance, definitive diagnosis of CHD with extracardiac findings will help the surgeons to plan complex surgeries and identify postsurgical complications. Both MDCT and TTE are not always available in single institute; so by calculating the agreement between them, we can help in making decision about imaging investigation of patients with $\mathrm{CHD}$ leading to correct diagnosis.

The objective of this study was to determine the degree of agreement between multidetector computed tomography angiography and transthoracic echocardiography in diagnostic evaluation of congenital heart disease with extracardiac findings.

\section{METHODOLOGY}

This cross-sectional study was conducted in Radiology Department, Doctors Hospital and Medical Centre, from May to November 2016, after taking approval from the Ethical Review Committee of the Hospital and written informed consents from the patients. Sample size of 150 cases was calculated with $95 \%$ confidence level and $8 \%$ margin of error and taking the expected agreement of $84 \%$ between CT and TTE in evaluation of congenital heart disease with extracardiac findings. ${ }^{19}$

All 150 patients who were referred by clinicians to Radiology Department of author's hospital, fulfilling the inclusion/exclusion criteria, were selected.
Inclusion criteria consisted of patients, both male and female (aged between 1 - 16 years), who were clinically suspected (e.g. cyanosis, murmurs, failure to thrive) to have a cardiovascular malformation and referred to author's department by clinician were included in the study. Exclusion criteria consisted of patients with acquired cardiac disease like rheumatic heart disease. Assessment was based on history of rheumatic fever followed by valvular disease and clinical evaluation showing sequelae of rheumatic fever. Patients with previous documented allergic reaction to contrast medium used in CT angiography and patients with renal failure were also excluded. Renal failure was considered at GFR of $<50 \mathrm{ml} / \mathrm{min}$.

Both TTE \& MDCT angiography of the heart and extracardiac structures were performed using Toshiba Aplio Color Doppler scanner for TTE and 64-slice MDCT scanner for angiography. Each study was reviewed by one radiologist who was blinded to patient identification, for presence of congenital heart disease. The data obtained was recorded on a specially designed proforma, which contained two parts. Part 1 included patient data and part 2 contained study variables, i.e. CHD with findings of TTE and MDCT angiography recorded separately. Agreement was labelled in true positive and true negative patients.

Collected data was analysed through computer software SPSS version 16.0. Mean and standard deviation were calculated for quantitative variables, i.e. age. Frequency and percentage was calculated for qualitative variables i.e. gender, CHD on TTE and MDCT angiography and their agreement. Effect modifiers like age, gender and type of CHD (extracardiac / intracardiac) were controlled through stratifications. Kappa statistics was used to see the strength of agreement between TTE and MDCT angiography in the diagnosis of $\mathrm{CHD}(\mathrm{k}=-0.113$ and $\mathrm{p}=0.088)$.

\section{RESULTS}

One hundred and fifty patients were included in the

Table I: List of types of CHD seen in study with MDCT and TTE findings.

\begin{tabular}{|c|c|c|}
\hline & MDCT findings & TTE findings \\
\hline \multicolumn{3}{|l|}{ Aorta: } \\
\hline Coarctation & $\begin{array}{l}\text { Luminal narrowing of proximal aorta. } \\
\text { Collaterals may be seen. }\end{array}$ & $\begin{array}{l}\text { Luminal narrowing of proximal aorta with increased systolic and diastolic } \\
\text { velocities across the stenosis. }\end{array}$ \\
\hline \multicolumn{3}{|l|}{ Pulmonary arteries: } \\
\hline Artesia & Lack of luminal continuity. & $\begin{array}{l}\text { Lack of luminal continuity and absence of blood flow from the right } \\
\text { ventricle to the pulmonary artery. }\end{array}$ \\
\hline Ductus arteriosus & Ductus bump connecting to pulmonary artery. & Diastolic flow reversal in descending and abdominal aorta. \\
\hline Transposition of great arteries & $\begin{array}{l}\text { Great vessels lie parallel to each other in the } \\
\text { same sagittal plane. }\end{array}$ & Great vessels lie parallel to each other in the same sagittal plane. \\
\hline Truncus arteriosus & $\begin{array}{l}\text { Common arterial trunk originating from both } \\
\text { ventricles. High VSD immediately below truncal valve. }\end{array}$ & $\begin{array}{l}\text { Common arterial trunk originating from both ventricles. High VSD } \\
\text { immediately below truncal valve. Bidirectional flow across VSD. Truncal } \\
\text { valve regurgitation. }\end{array}$ \\
\hline \multicolumn{3}{|l|}{ Pulmonary veins: } \\
\hline $\begin{array}{l}\text { Anomalous pulmonary } \\
\text { venous return }\end{array}$ & Lack of connection of pulmonary veins to left atrium. & Lack of connection of pulmonary veins to left atrium. \\
\hline
\end{tabular}


study. The mean age of the patients was $6.6 \pm 6.0$ years. There were $77(51.3 \%)$ patients in the age range of $1-4$ years, $20(13.3 \%)$ patients of age range of $5-8$ years, $12(8.0 \%)$ patients of age range of $9-12$ years, and 41 $(27.3 \%)$ patients of age range of $13-16$ years. There were $105(70 \%)$ male patients and $45(30 \%)$ female patients. The female to male ratio in this group was 1:2.3. Maximum number of patients, $n=68(45.3 \%)$, had pulmonary atresia and minimum number of patients seen had truncus arteriosus accounting for $3(2 \%)$ patients.

One hundred and forty, out of 150 patients, showed positive findings on CTA $93.3 \%$, while 10 patients (6.7\%) did not show positive finding. One hundred and fortyeight, out of 150 patients, showed positive findings on TTE $(78.7 \%)$ while 32 patients $(21.3 \%)$ did not show any positive finding. Agreement was found in $108(72 \%)$ patients, and not found in $32(21.3 \%)$ patients. There were $108(72 \%)$ cases that were found to be true positive and 0 cases were true negative. Kappa statistic showed $K=-0.100$ in males and $K=-0.140$ in females, with $p=0.182$ and 0.295 , respectively. There was found a poor agreement.

Stratification of agreement with respect to age group showed $K=-0.072$ and $p=0.329$ in age group 1-4 years, $K=-0.176$ and $p=0.430$ in age group 5-8 years. $K=-0.154$ and $p=0.460$ in age group $9-12$ years. $K$ and $p$-values could not be calculated for age group 13-16 years because no negative cases were observed on CTA. Stratification of agreement with respect to type of CHD showed $K=-0.105$ and $p=0.672$ in patients with Coarctation of aorta. $K=-0.102 \& P=0.273$ in patients with pulmonary atresia. $K=-0.333$ and $p=0.505$ in patients with tricuspid atresia. $K=-0.286$ and $p=0.180$ in patients with transposition of great arteries. $\mathrm{K}=-0.091$ and $p=0.645$ in patients with tetralogy of Fallot's. K and $P$ values could not be calculated in patients with anomalous pulmonary venous return and patent ductus arteriosus because no negative cases were observed on CTA. $K$ and $p$-values could not be calculated in patients with Truncus arteriosus because no negative cases were observed on both TTE and CTA.

\section{DISCUSSION}

Detecting extracardiac manifestations of congenital heart disease often presents a challenge in diagnosis. Congenital heart diseases with extracardiac findings include major structural malformations of the heart and/or major vessels present at or persisting abnormally after birth. CHD with extracardiac findings are listed in Table I. Although conventional radiography may give some idea about the type of congenital heart disease, it is significantly limited in delineating the anatomy and exact pathology. 20 Echocardiography and CT angio- graphy are, therefore, used to properly evaluate such disease. Echocardiography is usually first line of investigation used to image the heart.21,22 However, due to its limited window availability, echocardiography often fails to detect some of the more complex extracardiac manifestations of congenital heart disease.23 CT angiography offers greater benefit due to its crosssectional imaging ability. Both modalities reliably show abnormal anatomy or structural defects according to type of congenital cardiac disease. In this study, TTE could detect $78.7 \%$ cases; and CT angiography could detect $93.3 \%$ cases. Thus CT angiography showed a higher sensitivity in detecting extracardiac findings of congenital heart disease. A study done by Bu G, et al. showed the sensitivity of CTA in diagnosing complex CHD being $93 \%$ and that of TTE being $68 \% .24$ The observed sensitivities show that TTE has higher probability of misdiagnosis when evaluating extracardiac findings of CHD.

This study was a comparison of ability of transthoracic echocardiography and CT angiography in detecting extracardiac findings of congenital heart disease in a sample size of 150 patients. The results showed that CT angiography could detect extracardiac findings of congenital heart disease in a higher frequency as compared to transthoracic echocardiography and both the studies showed substantial disagreement.

In this study, the most common extracardiac finding of congenital heart disease was pulmonary atresia $(45.3 \%)$, followed by TGA $(12.0 \%)$. TTE could detect $78.7 \%$ cases; and CT angiography could detect $93.3 \%$ cases. Thus, CT angiography showed a higher sensitivity in detecting extracardiac findings of congenital heart disease. A study done by $\mathrm{Bu} \mathrm{G}$, et al. showed the sensitivity of CTA in diagnosing complex CHD being $93 \%$ and that of TTE being $68 \% .25$ The observed sensitivities show that TTE has higher probability of misdiagnosis when evaluating extracardiac findings of CHD.

In this study, the most common extracardiac finding of congenital heart disease was pulmonary atresia (45.3\%). The least common type was truncus arteriosus occurring only $2 \%$.

Majority of patients in study belonged to age group of 1-4 years comprising $51.3 \%$ of patients and least number of patients were seen in age group of 9-12 years comprising only $8 \%$ of patients. Mean age was 2.1 years and median was 01 year.

This study had few limitations. First, the findings of both the studies could not be compared to surgical findings. Second, although CTA can show good anatomy, it cannot outline the hemodynamic status of the great vessels and their anomalies. Thirdly, TTE has limited role in demonstrating extracardiac structures. Diagnosing 
and treating $\mathrm{CHD}$ is important which improves the quality of life and decreases both mortality and morbidity. Echocardiography, being widely available, is usually the first line modality used to evaluate the CHD. However, in addition to being highly operator dependent, it has limited role in evaluating extracardiac findings associated with CHD due to acoustic window limitations. CT angiography, instead of having a side effect of radiation exposure, more reliably diagnoses extracardiac findings of $\mathrm{CHD}$.

\section{CONCLUSION}

Relatively poor agreement was observed in CTA and TTE for evaluation of extracardiac findings of CHD. CTA should be a first line modality for detection of extra cardiac findings of CHD.

\section{DISCLOSURE:}

This article is extracted from dissertation of corresponding author, submitted to CPSP as requirement of Fellowship.

\section{ETHICAL APPROVAL:}

This study was approved by Ethical Review Board of Doctors Hospital and Medical Centre, Lahore.

\section{PATIENTS' CONSENT:}

Informed consents are obtained from patients to publish the data.

\section{CONFLICT OF INTEREST:}

Authors declared no conflict of interest.

\section{AUTHORS' CONTRIBUTION:}

AAM: Data collection, compiling, statistics, discussion, correspondence.

FA: Case reporting and data referral.

SA: Data collection, literature review.

JA: Supervision and revision.

KF: Supervision and final approval.

\section{REFERENCES}

1. Bernier PL, Stefanescu A, Samoukovic G, Tchervenkov Cl. The challenge of congenital heart disease worldwide: Epidemiologic and demographic facts. Semin Thorac Cardiovasc Surg Pediatr Card Surg Annu 2010; 13:26-34.

2. Kaltman JR, Burns KM, Pearson GD. Perspective on congenital heart disease research. Circ Res 2017; 120:898-900.

3. Van der Linde D, Konings EE, Slager MA, Witsenburg M, Helbing WA, Takkenberg JJ, et al. Birth prevalence of congenital heart disease worldwide: A systematic review and meta-analysis. J Am Coll Cardiol 2011; 58:2241-7.

4. Marelli A, Ionescu-lttu R, Mackie A, Guo L, Dendukuri N, Kaouache $M$. Lifetime prevalence of congenital heart disease in the general population from 2000 to 2010. Circulation 2014; 130:749-56.
5. Hassan I, Haleem A, Bhutta Z. Profile and risk factors for congenital heart disease. J Pak Med Assoc 1997; 47:78-81.

6. Holst K, Said S, Nelson T, Cannon B, Dearani J. Current interventional and surgical management of congenital heart disease. Circ Res 2017; 120:1027-44.

7. Jenkins KJ, Castañeda AR, Cherian KM, Couser CA, Dale EK, Gauvreau K, et al. Reducing mortality and infections after congenital heart surgery in the developing world. Pediatrics 2014; 134:e1422-30.

8. Panchal S. Fetal echocardiography. Ultrasound Obstet Gynecol 2014; 297.

9. Velzen C, Clur S, Rijlaarsdam M, Bax C, Pajkrt E, Heymans M, et al. Prenatal detection of congenital heart disease - Results of a national screening programme. BJOG 2016; 123:400-7.

10. Koestenberger M. Transthoracic echocardiography in children and young adults with congenital heart disease. ISRN Pediatrics 2012; 2012:753481.

11. Burchill L, Huang J, Tretter J, Khan A, Crean A, Veldtman G, et al. Noninvasive imaging in adult congenital heart disease. circulation research. 2017; 120:995-1014.

12. Dillman J, Hernandez R. Role of $C T$ in the evaluation of congenital cardiovascular disease in children. AJR Am J Roentgenol 2009; 192:1219-31.

13. Mehta R, Lee K, Chaturvedi R, Benson L. Complications of pediatric cardiac catheterization: $A$ review in the current era. Catheter Cardiovasc Interv 2008; 72:278-285.

14. Vasanawala S, Hanneman K, Alley M, Hsiao A. Congenital heart disease assessment with 4D flow MRI. J Magn Reson Imaging 2015; 42:870-86.

15. Duan $Y$, Wang X, Cheng Z. Application of prospective ECGtriggering dual-source CT angiography in infants and children with congenital heart disease. Zhonghua Yi Xue Za Zhi 2012; 92:179-83.

16. Molaie A, Abdinia B, Zakeri R, Talei A. Diagnostic value of chest radiography in pediatric cardiovascular diseases: $A$ retrospective study in Tabriz, Northwest of Iran. Int J Pediatr 2015; 3:9-13.

17. Lee T, Tsai I, Fu Y, Jan S, Wang C, Chang Y, et al. Using multidetector-row CT in neonates with complex congenital heart disease to replace diagnostic cardiac catheterization for anatomical investigation: Initial experiences in technical and clinical feasibility. Pediatr Radiol 2006; 36:1273-82.

18. Babu-Narayan S, Giannakoulas G, Valente A, Li W, Gatzoulis M. Imaging of congenital heart disease in adults. Eur Heart $J$ 2016; 37:1182-95.

19. Listijono D, Rubens M, Rigby M. Complementary use of imaging modalities in diagnosis of complex congenital heart disease. ASEAN Heart J 2014; 22:1.

20. Molaie A, Abdinia B, Zakeri R, Talei A. Diagnostic value of chest radiography in pediatric cardiovascular diseases: A retrospective study in Tabriz, Northwest of Iran. Int J Pediatr 2015; 3:9-13.

21. Qu Y, Liu X, Zhuang J, Chen G, Mai J, Guo X, et al. Incidence of congenital heart disease: The 9-year experience of the 
Guangdong registry of congenital heart disease, China. PLOS One 2016; 11:e0159257.

22. Bregman S, Frishman WH. Impact of improved survival in congenital heart disease on incidence of disease. Cardiol Rev 2018; 26:82-5.

23. Bu G, Miao Y, Bin J, Deng S, Liu T, Jiang H, et al. Comparison of 128-Slice low-dose prospective ECG-gated CT scanning and trans-thoracic echocardiography for the diagnosis of complex congenital heart disease. PLoS One 2016; 11: e0165617.

24. Mandalenakis Z, Rosengren A, Skoglund K, Lappas G, Eriksson $\mathrm{P}$, Dellborg M. Survivorship in children and young adults with congenital heart disease in Sweden. JAMA Int Med 2017; 177:224-30.

25. Triedman JK, Newburger JW. Trends in congenital heart disease: The next decade. Circulation 2016; 133:2716-33.

.......... 